\title{
Genome wide analysis of kinesin gene family in Citrullus lanatus reveals an essential role in early fruit development
}

\author{
Shujuan $\operatorname{Tian}^{\dagger}$, Jiao Jiang ${ }^{\dagger}$, Guo-qi Xu, Tan Wang, Qiyan Liu, Xiner Chen, Man Liu and Li Yuan ${ }^{*}$ (D)
}

\begin{abstract}
Background: Kinesin (KIN) as a motor protein is a versatile nano-machine and involved in diverse essential processes in plant growth and development. However, the kinesin gene family has not been identified in watermelon, a valued and nutritious fruit, and yet their functions have not been characterized. Especially, their involvement in early fruit development, which directly determines the size, shape, yield and quality of the watermelon fruit, remains unclear.
\end{abstract}

Results: In this study, we performed a whole-genome investigation and comprehensive analysis of kinesin genes in C. lanatus. In total, 48 kinesins were identified and categorized into 10 kinesin subfamilies groups based on phylogenetic analysis. Their uneven distribution on 11 chromosomes was revealed by distribution analysis. Conserved motif analysis showed that the ATP-binding motif of kinesins was conserved within all subfamilies, but not the microtubule-binding motif. 10 segmental duplication pairs genes were detected by the syntenic and phylogenetic approaches, which showed the expansion of the kinesin gene family in C. lanatus genome during evolution. Moreover, 5 CIKINs genes are specifically and abundantly expressed in early fruit developmental stages according to comprehensive expression profile analysis, implying their critical regulatory roles during early fruit development. Our data also demonstrated that the majority of kinesin genes were responsive to plant hormones, revealing their potential involvement in the signaling pathways of plant hormones.

Conclusions: Kinesin gene family in watermelon was comprehensively analyzed in this study, which establishes a foundation for further functional investigation of C. lanatus kinesin genes and provides novel insights into their biological functions. In addition, these results also provide useful information for understanding the relationship between plant hormone and kinesin genes in C. lanatus.

Keywords: Kinesin genes, Expression patterns, Early fruit development, Hormones response, Citrullus lanatus

\section{Background}

Kinesins, widely distributed in all eukaryotic organisms [1], are a group of microtubule-based motor proteins that move along microtubule (MT) protofilaments, powered by hydrolyzing ATP, to drive various essential biological processes [2]. All kinesin proteins share a

\footnotetext{
* Correspondence: Iyuan@nwafu.edu.cn

'Shujuan Tian and Jiao Jiang contributed equally to this work.

State Key Laboratory of Crop Stress Biology for Arid Areas, College of

Horticulture, Northwest A\&F University, Yangling 712100, Shaanxi, China
}

conserved motor domain of approximately 350 amino acids. The "motor head" domain consists of an ATPase catalytic site and MT-binding sites, which possesses catalytic ATPase and MT-binding abilities [3]. The kinesin family is classified as N-type, the middle and C-type kinesins respectively, with the motor head domain at or near the $\mathrm{N}$-terminus, in the middle, and close to the $\mathrm{C}$ terminus of the molecule. The "motor head" domain is followed by the stalk region and the "small globular tail" at the opposite end of the kinesin molecule. The "motor

(c) The Author(s). 2021 Open Access This article is licensed under a Creative Commons Attribution 4.0 International License, which permits use, sharing, adaptation, distribution and reproduction in any medium or format, as long as you give appropriate credit to the original author(s) and the source, provide a link to the Creative Commons licence, and indicate if changes were made. The images or other third party material in this article are included in the article's Creative Commons licence, unless indicated otherwise in a credit line to the material. If material is not included in the article's Creative Commons licence and your intended use is not permitted by statutory regulation or exceeds the permitted use, you will need to obtain permission directly from the copyright holder. To view a copy of this licence, visit http://creativecommons.org/licenses/by/4.0/ The Creative Commons Public Domain Dedication waiver (http://creativecommons.org/publicdomain/zero/1.0/) applies to the data made available in this article, unless otherwise stated in a credit line to the data. 
head" domain is responsible for protein movement powered by ATP hydrolysis [4-6]. And the "stalk/tail" domain is important for the interaction with subunits of the holoenzyme or with the cargo molecules $[4,7,8]$. The short "neck" region between the "head" and "stalk/ tail" is essential for functions such as the direction of motility or regulation of activity [9]. The motor domain is well conserved in each kinesin subfamily, whereas the stalk/tail region outside the motor domain is highly divergent even in the same subfamily, reflecting the diverse biological functions even within the same subfamily.

Based on phylogenetic analysis using the conserved motor domain sequences, the kinesins are divided into fourteen families, designated as kinesin-1 to kinesin-14. Kinesins that do not belong to any of these subfamilies are considered as orphans, but most kinesins identified can easily be assigned to a specific family [10]. Most members of kinesin families have an $\mathrm{N}$-terminal motor domain named as $\mathrm{N}$-type kinesins whereas few families have an internal motor domain or a C-terminal motor domain. The directionality of kinesins varies between families, which is sometimes correlated with the position of the motor domain. In general, kinesins with the Nterminal motor domain travel to the plus ends of MTs whereas the $\mathrm{C}$-terminal motors move toward the minus ends of MTs [11-14].

Previous expression profiles analysis revealed that plant kinesin genes play important roles in fruit development. In apple (Malus domestica Borkh.) cultivar Fuji, the kinesin gene KIN2 was strongly expressed in early stage of fruit development [15]. Further investigation showed that KIN2 gene was also expressed primarily in two other apple genotypes "Gala" and "Golden Delicious" [16]. This demonstrated that the kinesin gene KIN2 carries out regulatory role in early fruit development in apple. In cucumber, the kinesin genes CsKF1-7 were highly expressed during early fruit development and involved in rapid cell division or expansion [17]. Moreover, the CsKF1 and CsKF3 were dramatically active in the fruit elongation stages, implicating their essential roles in the fruit length regulation in cucumber [18]. Intriguingly, in tomato (Solanum lycopersicum), the kinesin gene SpPAKRP was predominantly expressed in the placenta tissue in the 4-DPA (Days Post Anthesis) fruit, so $\operatorname{SPPAKRP}$ is likely involved in controlling early fruit development by regulating placenta development $[19,20]$. The watermelon fruit as well as tomato is classified as a berry fruit and the edible parts of the fruit develop from placenta [21]. In addition, the size, yield and quality of the cucurbits fruit depend on the regulation of the placenta during early fruit development [22-24]. So, identification and the functional analysis of kinesin is the ideal entry point for exploring molecular mechanism of kinesin genes in regulating watermelon early fruit development. Moreover, other kinesin genes have been verified to participate in different biological functions, including root, stem and leaf various vegetative tissues development genes (e.g., DBS1, BC12/GDD1, AtKINESIN-4A/FRA1) [25-28]; plus anther, male gametophyte, embryo, endosperm and seed development genes ( e.g., SRS3 and NtKRP) [29-31]. These works revealed the critical roles of plant kinesins in many essential processes in plant development, including not only plant vegetative growth but also plant reproductive process. However, up to now, little is known about kinesin family genes in watermelon. And very few kinesins have been functionally identified during early fruit development. Therefore, it is well worthy to extensively investigate their roles in economic crops, like watermelon.

Watermelon is the fifth consumed fresh fruit in the world. It is a highly nutritional valued fruit, known as "the king of summer fruits". The early fruit development directly determines the size, shape, yield and quality of the watermelon fruit. Considering the involvement of kinesin genes in early fruit development via regulating placenta development in tomato $[19,20]$, genome-wide study of the kinesin genes in watermelon is the ideal pointcut for exploring their real roles in the critical developmental processes, especially in watermelon early fruit development. Thus, kinesin genes were analyzed in the Citrullus lanatus genome in this study. The phylogenetic relationships, gene structure, chromosomal locations, and conserved motifs of the encoded proteins were also investigated. The tissue-specific expression patterns of all ClKINs genes in watermelon were further studied, as well as ClKINs expression under hormonetreated condition. Particularly, five ClKINs genes showed specific and abundant expression in early fruit development stage. Our work provides useful information regarding the molecular mechanism of kinesin genes regulating early fruit development and a new insight into the yield and quality control mechanism in watermelon.

\section{Results \\ Genome-wide identification of kinesin genes in Citrullus lanatus}

A total of 63 candidate genes were identified from the watermelon genome (Cucurbit Genomics Database, http://www.icugi.org/) based on amino acids sequence analysis. 15 candidate genes didn't contain conserved kinesin motor domain and then were excluded from further analysis. In addition, these remaining 48 Kinesin genes can also be verified by hidden Markov models (HMMs) analysis search of function conserved Pfam domains, which was consistent with the above sequence similarity blasting. In conclusion, 48 kinesin genes with 
complete and functional structures are presented in the watermelon genome, designated as ClKINs hereafter.

To explore basic properties of each kinesin, the lengths of genome DNA and protein sequences, the numbers of the introns and exons, the isoelectric point and the theoretical molecular weight were predicated, respectively (Table S1). The kinesin genes in Citrullus lanatus genome have coding sequence lengths of 9278670 base nucleotides, encoding proteins length ranged from 308 to 2889 amino acids with predicted molecular weight in the range of $25.0-330.3 \mathrm{KDa}$. The theoretical isoelectric point calculation indicated that the kinesin protein isoelectric points $(\mathrm{pI})$ were distributed in the range of 5.10-9.65 (Table S1).

In order to characterize the distribution of kinesin genes in the watermelon genome, the physical locations of kinesin genes on the watermelon chromosomes were further investigated. 48 kinesin genes were mapped to the 11 chromosomes (Fig. 1), exhibiting an uneven distribution in the watermelon genome. Chr10 contains the maximum numbers of 8 kinesin genes, while only two genes locate on Chr7. The other chromosomes, including Chr1, Chr2, Chr3, Chr4, Chr5, Chr6, Chr8, Chr9, Chr11, contain 3-6 kinesin genes, respectively.

\section{Phylogenetic analysis of kinesin family}

To estimate the phylogenetic relationships of watermelon kinesins to other known kinesins in different plants, multiple sequence alignment of watermelon kinesins motor domain sequences to the sequences from dicotyledonous model plant, $A$. thaliana, and monocotyledonous crop, $O$. sativa, was conducted using the software MUSCLE and the phylogenetic tree of these kinesins was then generated with MEGA 6.06 using neighbor joining method (Fig. 2). The phylogenetic analysis suggested that kinesin proteins from three different species can be categorized into 10 families: KIN1, KIN4, KIN5, KIN7, KIN8, KIN10, KIN11, KIN12, KIN13,
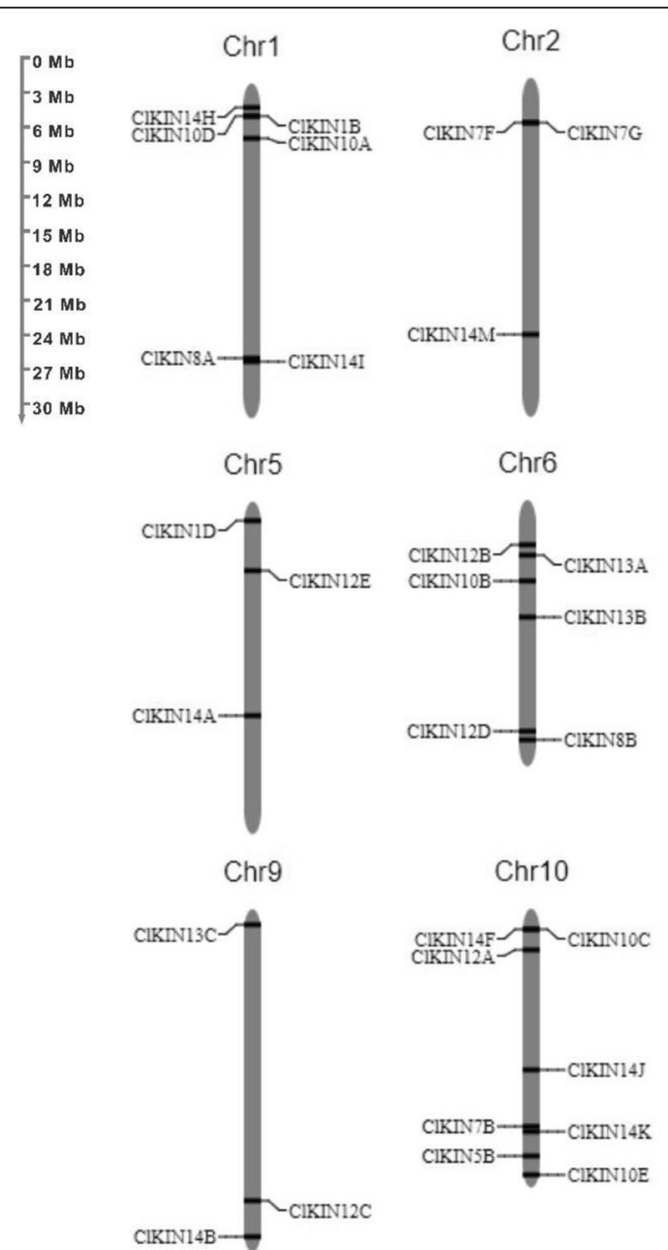
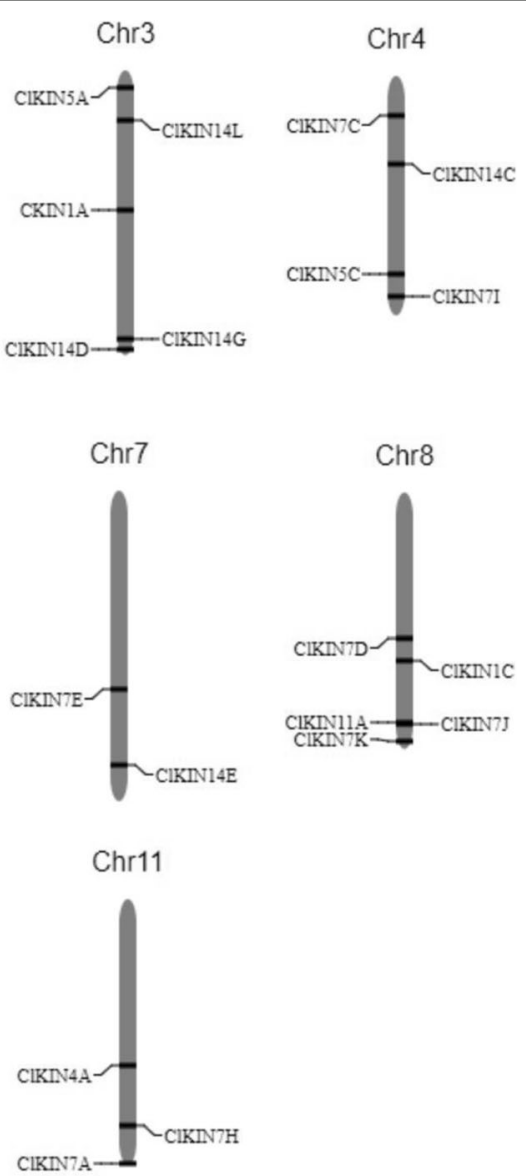

Fig. 1 Distribution of Citrullus lanatus kinesin genes on 11 chromosomes. Chromosome numbers were marked as Chr1- Chr11 at the top of each chromosome. The sizes of chromosome were labeled on the left of the figure. Forty-eight kinesin genes of watermelon were mapped to different chromosomes using Map Chart 


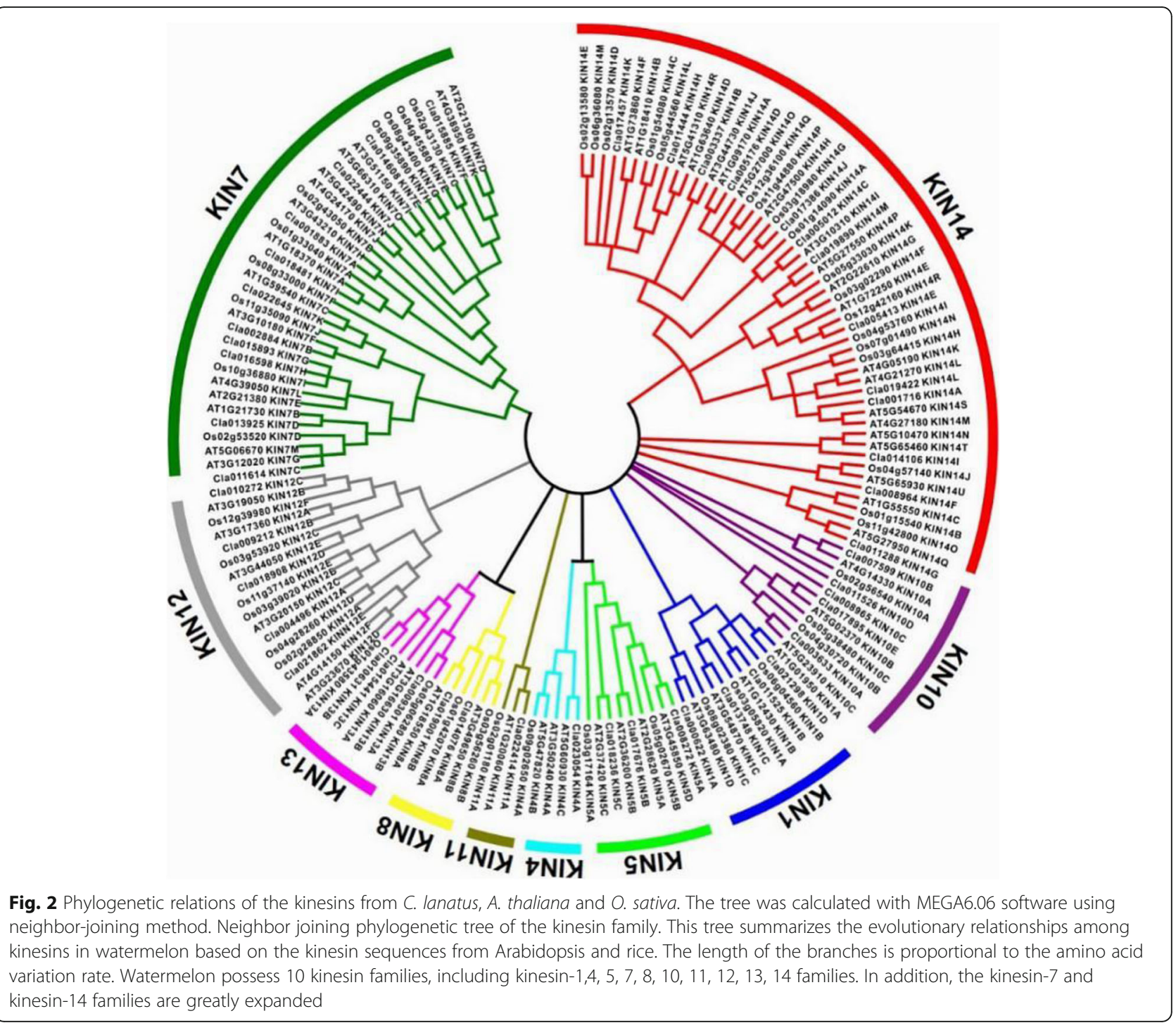

KIN14 (Figure S1 and Figure S2). Among them, the KIN14 family is the largest family consisting of 52 kinesins. The KIN7 family is the second largest family, which has 36 kinesin members. KIN11 is the smallest family with only 3 kinesins. Kinesin numbers from watermelon followed the same distribution tendency as the other two species. 13 watermelon kinesins belong to the KIN14 subfamily which is the largest family of all. 7 kinesins are grouped into KIN7, the second largest subfamily. Only 1 kinesin is in KIN11 family, representing the smallest subfamily. To further explore the evolutionary relationships among kinesin in fruit plants, we identified 53 kinesin homologs from fruit plant tomato. The phylogenetic analysis showed that the kinesin-14 and 7 subfamilies were expanded during evolution, which is consistent with Arabidopsis and rice (Figure S3). The phylogenetic relationship does not show any recognizable distinction between dicot and monocot species analyzed, indicating functional conservation of kinesin throughout plant kingdom.

\section{Gene structure and conserved motif distribution analysis of watermelon kinesin family genes}

The gene structure and intron/exon arrangements of the ClKINs genes were determined by the comparison of the cDNA sequence of each ClKIN with its genomic DNA sequence. The analysis results revealed that the intron number of all ClKINs genes ranged from 4 to 34 . ClKIN14F only has 4 introns while there are 34 introns presented in ClKIN12C (Fig. 3).

Multiple sequence alignment of watermelon kinesin protein sequences was performed and analyzed using MEME online software to explore sequence features and functional motifs of each CIKIN protein. Seven typical conserved motifs for kinesin family proteins, named as motifs $1-7$, have been identified (Fig. 4). Motif 1 , highly 


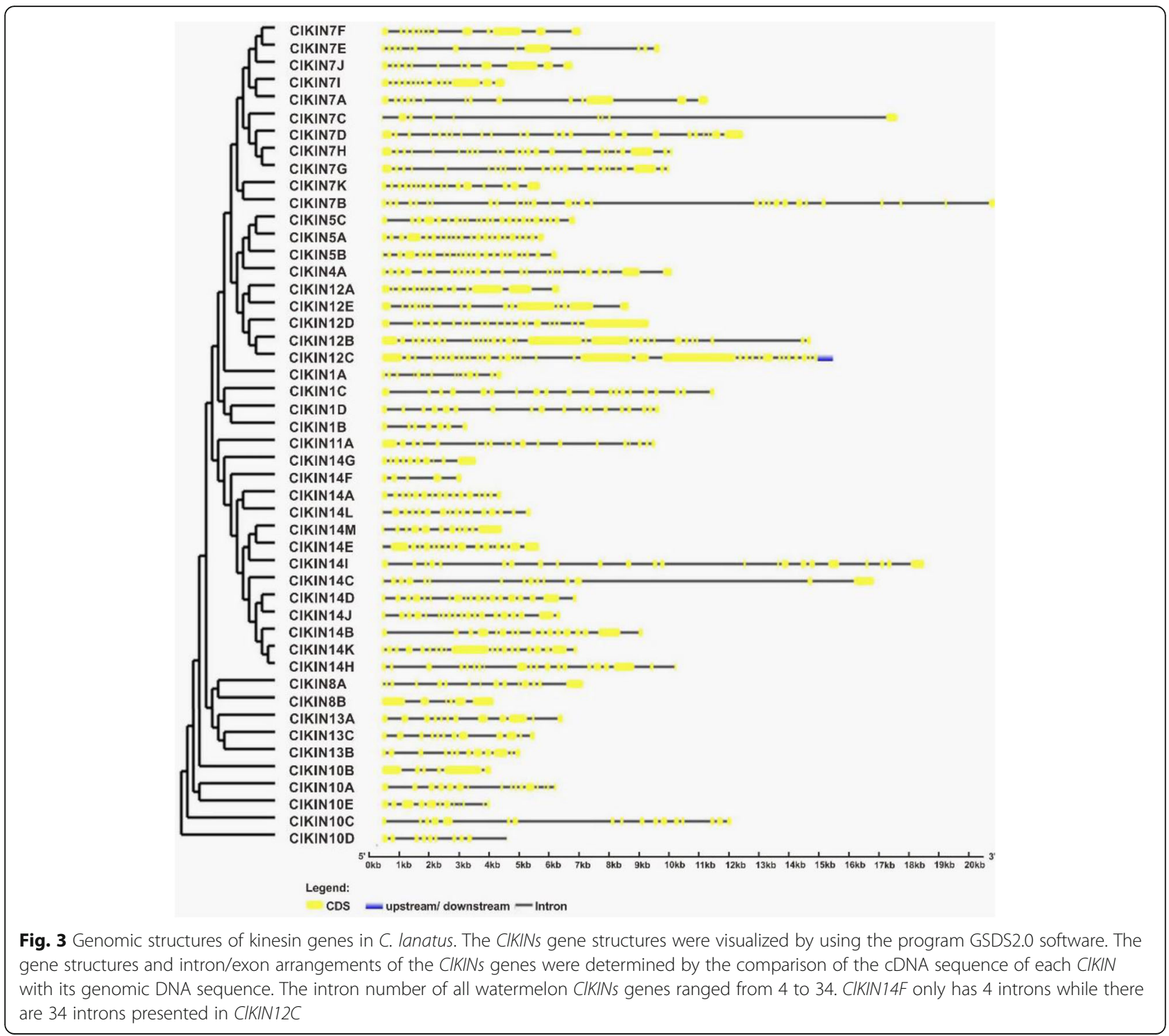

conserved peptide sequence (FAYGQTGSGKT) inside the ATP-binding site and motif 6, a conserved microtubule-binding site (SSRSH), were found in all watermelon kinesins. Motif 4, another conserved microtubule-binding site 'VDLAGSE', could be detected in most ClKINs with the exception of CIKIN7C, ClKIN10D, ClKIN14A and CIKIN14C [32]. The motif 2, the microtubule-binding site 'HIPYR' existed in most CIKINs with the exclusion of CIKIN1D, CIKIN7C, ClKIN10D, ClKIN12A, ClKIN14M and ClKIN14G. Motif 3 is a conserved motif of K/RxIxNxxxVIN at the beginning of the neck region. Motif 5 is the highly conserved neck motif consisting of a hydrophobic repeat pattern of $\varnothing-\mathrm{xx}(\mathrm{x})-\varnothing-\mathrm{xxx}-\varnothing-\mathrm{xx}-\varnothing-\mathrm{G}$. Motif 3 and Motif 5 were presented in the majority of CIKINs [33]. The results showed that CIKINs proteins contained the typical conserved feature motifs of kinesin family.
Duplication and syntenic analysis of kinesin gene families Tandem and segmental duplications play important roles in the expansion and function of a gene family $[34,35]$. To reveal the possible evolutionary relationships of kinesin gene families, duplication events, segmental and tandem duplication gene pairs of the kinesin family were investigated in $C$. lanatus and $A$. thaliana. The results implied that there are no tandem genome duplication events occurred for kinesin genes. However, 15 pairs of segmental duplication events were identified, where each pair of genes were situated at separate chromosome in watermelon genome, such as ClKIN1B/ClKIN1D, ClKIN7F/ClKIN7J, ClKIN14L/ ClKIN14A, ClKIN13B/ ClKIN13C (Fig. 5). Overall, the synteny analyses suggested that the kinesin family in watermelon expanded only through segmental duplications. 


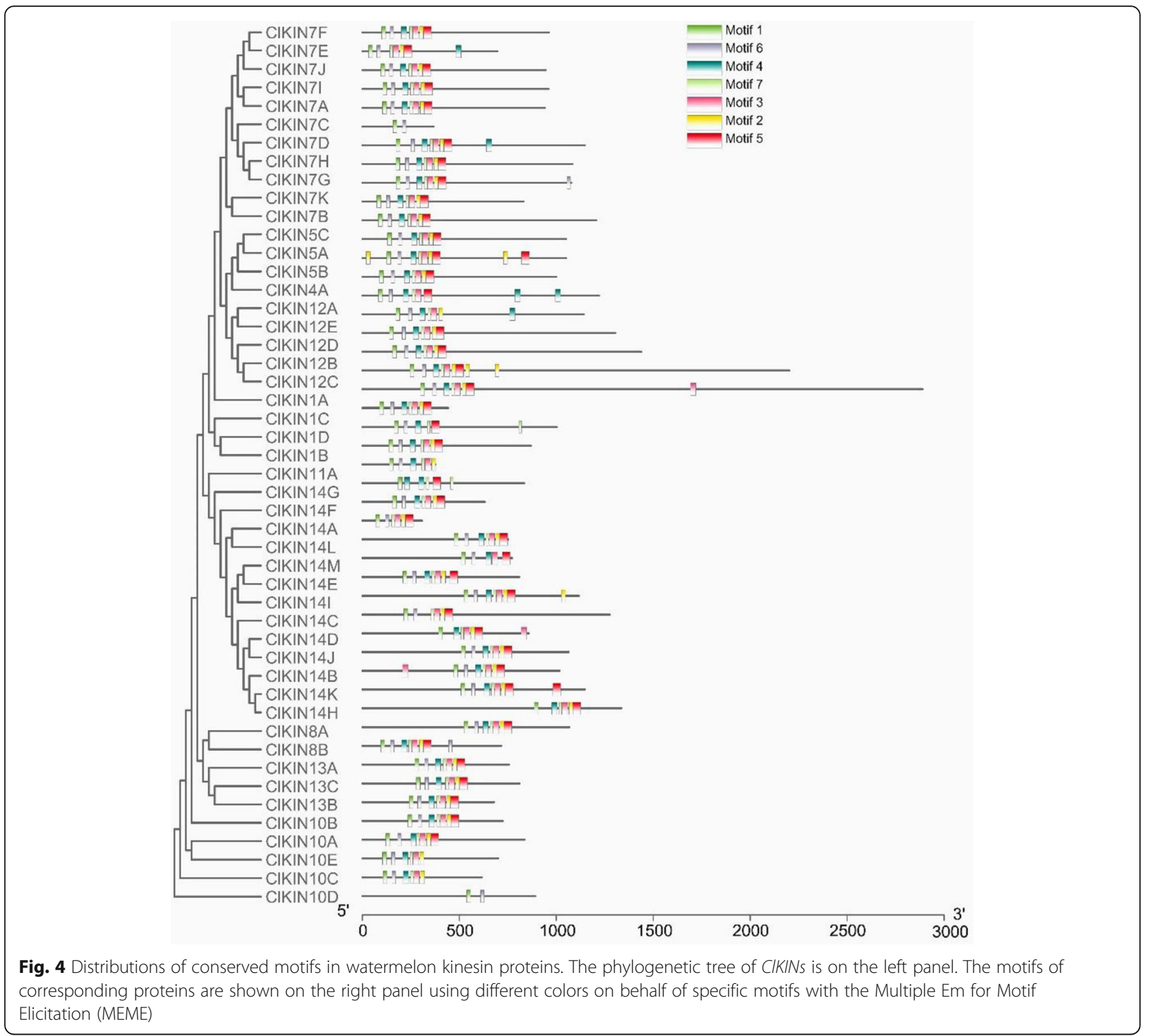

\section{Expression profiles of kinesin genes in different tissues in} watermelon

The expression pattern is important for assessing the potential roles of ClKINs genes in the processes of plant growth and development. Therefore, we examined the expression patterns of $48 \mathrm{ClKINs}$ genes in five different tissues including the root, stem, leaf, female and male flower by quantitative reverse transcription PCR (qRTPCR) (Fig. 6). The qRT-PCR results indicated that the kinesin genes in watermelon exhibited a restricted expression pattern and could only be detected in one or two tissue tested. Eight watermelon kinesin genes (Cla013748, Cla001716, Cla003337, Cla011614, Cla000622, Cla008965, Cla016598 and Cla010272) were highly expressed in the root, stem and leaf vegetative organs, which indicates their potential roles in vegetative organs development. In addition, 20 kinesin genes were preferentially expressed in the female flower. And 9 kinesin genes were specifically expressed in the male flowers. Overall, 38 kinesin genes were abundantly expressed in the reproductive organs, suggesting that they play critical roles in the growth and development of reproductive tissues.

\section{Key kinesin genes identification involved in early fruit development}

Fruit development of watermelon, as a cucurbit species, follows the canonical developmental progression of four stages: ovary development; fruit set; expansive fruit growth; maturation and ripening [21, 22, 36]. Among the four stages, the first three stages of development (ovary development, fruit set, expansive fruit growth) are 


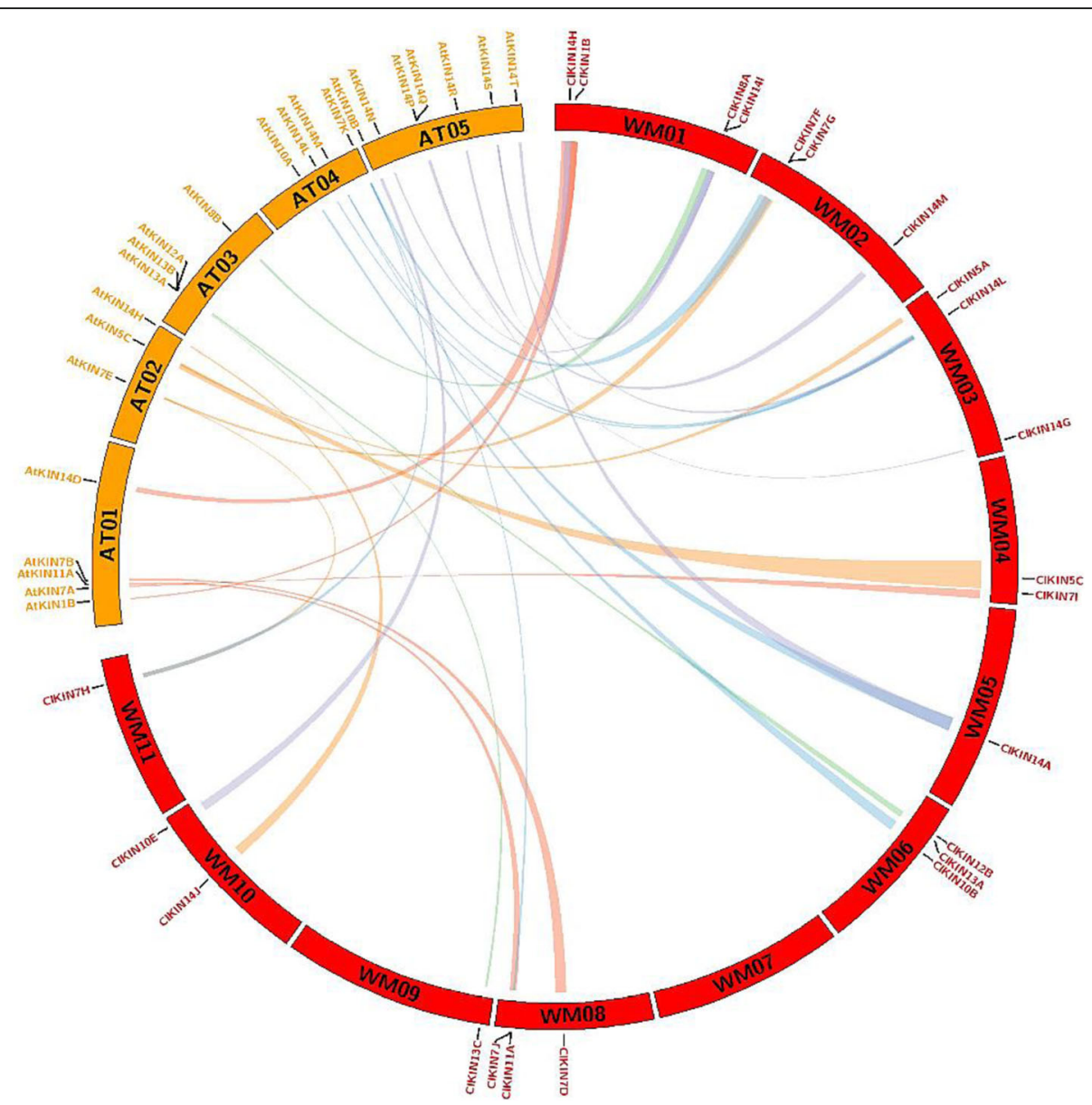

Fig. 5 Synteny analysis between watermelon and Arabidopsis kinesin genes. Chromosomes of watermelon and Arabidopsis are shown in different colors (red and yellow) and in partial circles. The approximate distribution of each kinesin gene is presented by short black line on the circle. Colored curves indicate the syntenic relations between watermelon and Arabidopsis kinesin genes. The prefixes 'WM' and 'AT' respectively indicate watermelon Citrullus lanatus and Arabidopsis thaliana

defined as the early fruit development stage. The early fruit development stage completes in about 10 days after pollination (DAP) and directly determines the size, shape and quality of fruit [37]. In addition, previous transcriptome and qRT-PCR analysis results demonstrated that kinesin family genes participated in the regulation of early fruit development in Malus domestica and Cucumis sativus $[15,17]$. Therefore, to identify potential roles of kinesin family genes in the process of watermelon early fruit development, qRT-PCR was performed using cDNA prepared from the fruits at $-1,0,1,2,3,5,7,9$, $10,12,34$ days after pollination (DAP). Hierarchical clustering and heatmap analysis were executed and gave a visual analysis of kinesin gene expression. From the overview of the kinesin expression profiles, the transcripts of all ClKINs genes tested could be detected in the fruit at different development stages, with different transcription levels at specific stage of fruit development (Fig. 7). Among them, 21 ClKINs showed high transcription levels in the fruits at 34 days DAP, which is at maturation and ripening development phase. A total of 27 ClKINs exhibited different expression levels in the fruits at- $1,0,1,2,3,5,7,9,10,12$ days DAP, which is at the early fruit development stage. Further detailed analysis revealed that 14 kinesins (Cla022645, Cla013925, Cla010272, Cla009301, Cla019890, Cla007599, Cla014608, Cla014076, Cla000622, Cla018908, Cla014106, Cla015441, Cla022444 and Cla008965) showed specifically or abundantly expressed in the early developing fruits. Moreover, the major edible sections of watermelon fruit develop and differentiate from the pistil tissue. In consequence, comparative analysis of expression levels between the early fruit and the pistil tissue demonstrated that 5 kinesin ClKINs genes (Cla022645, Cla013925, Cla019890, Cla007599 and Cla018908) showed relatively specific or highest expression level simultaneously both in the early developmental fruit and pistil. To better associate the functions of kinesin gene family in the early fruit development, we also examined the expression levels of 5 ClKINs genes in Chinese 


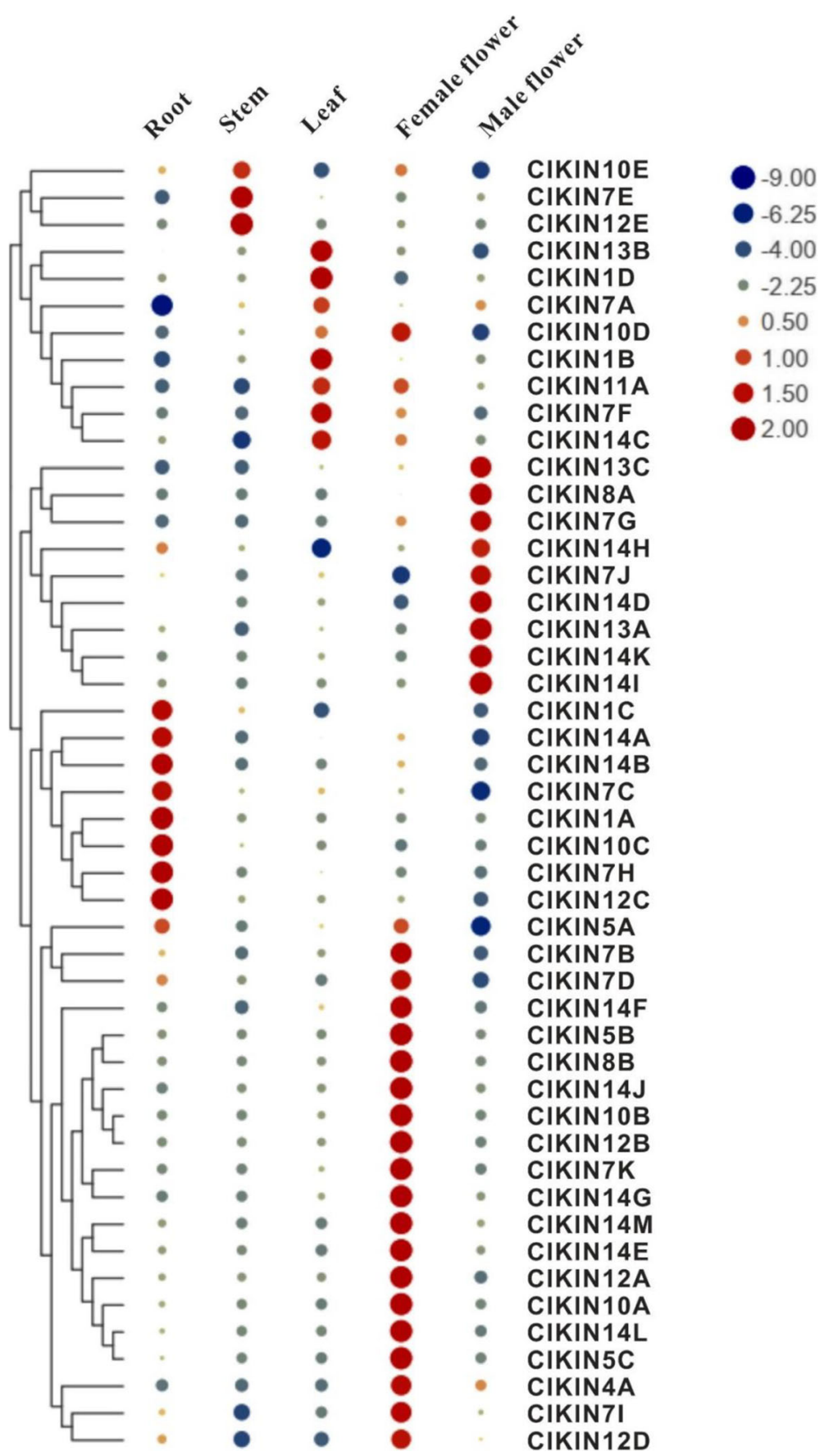

Fig. 6 Expression profiles analysis of kinesin family in different tissues in watermelon. The data were showed as means value \pm SD. All experiments were performed with three independent replicates. $\log _{2}$-transformed data were used for the cluster analysis $(n=3)$. The inset shows the colour legend used in the cluster representation ( $\log _{2}$ ratios). The red dots indicate the higher expression level, whereas the blue dots indicate the lower expression level. CIACTIN gene was used for normalization of quantitative qRT-PCR results

watermelon 97,103 which is round and medium-size fruit shape comparing to watermelon YL with the long and big fruit shape by qRT-PCR. The results indicated that 5 ClKINs genes abundantly expressed in the early fruit development stage, especially in the fruits at 1 DAP (Fig. 8). The expression of 5 ClKINs genes were further analyzed in seeds at different DAP. And 5 ClKINs genes showed different expression levels in seeds. Especially, ClKIN7D and ClKIN12D showed higher expression levels in seeds at 6 and 8 days after pollination (Figure S4). The results suggested that 5 ClKINs genes (ClKIN7D, ClKIN7K, ClKIN1OB, ClKIN12D and 

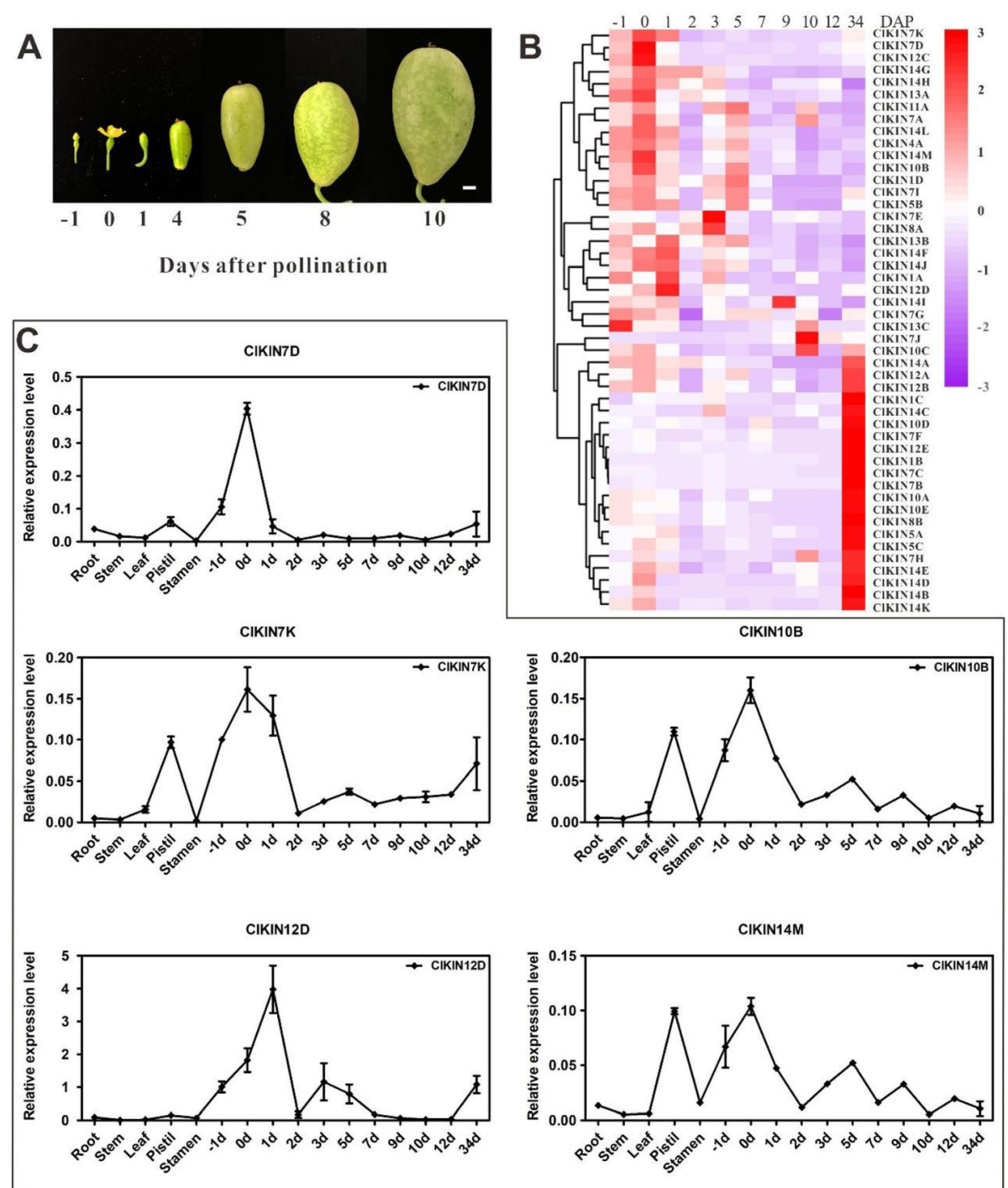

Fig. 7 Expression profiles analysis of CIKINs genes during the early fruit development in watermelon. a The morphological characteristics of the watermelon fruits at different days after pollination. $-1,0,1,4,5,8,10$ respectively displays the days after pollination. $\mathbf{b}$ Expression patterns of CIKINs genes during the fruit development. Log $_{2}$-transformed data were used for the cluster analysis $(n=3)$. The inset shows the colour legend used in the cluster representation ( $\log _{2}$ ratios). A red box indicates the higher expression level, whereas the purple box indicates the lower expression level. CIACTIN gene was used for normalization of quantitative gRT-PCR results. c The dynamic changes of expression levels analysis from the 5 CIKINs genes specifically or abundantly expressed in the early fruit development. The standard deviations of three biological replicates are represented by the error bars

ClKIN14M) are involved in fruits/seed development during the early fruit development.

In order to accurately examine ClKINs genes tissue expression patterns and verify genes functions, 3 of the above 5 genes (ClKIN1OB, ClKIN12D and ClKIN14M) were selected for further verification by in situ hybridization assay. Detailed analysis showed that ClKIN1OB, ClKIN12D and ClKIN14M have strong expression in early fruit/seeds development (Fig. 9). All these data indicated that the different kinesin members displayed diverse expression patterns and may have stage-specific roles during watermelon fruit/seed development. Especially, the 3 kinesin genes tested may function in the process of watermelon early fruit/seed development.

\section{Potential roles of kinesin family genes in response to hormone treatments}

To understand the possible relationship between watermelon kinesin genes and major hormones, the relative transcriptional levels of each kinesin gene were investigated after ABA and ETH hormones treatments. The heat map was created based on the relative expression levels (Fig. 10). The results revealed that at least $1 / 3$ of 

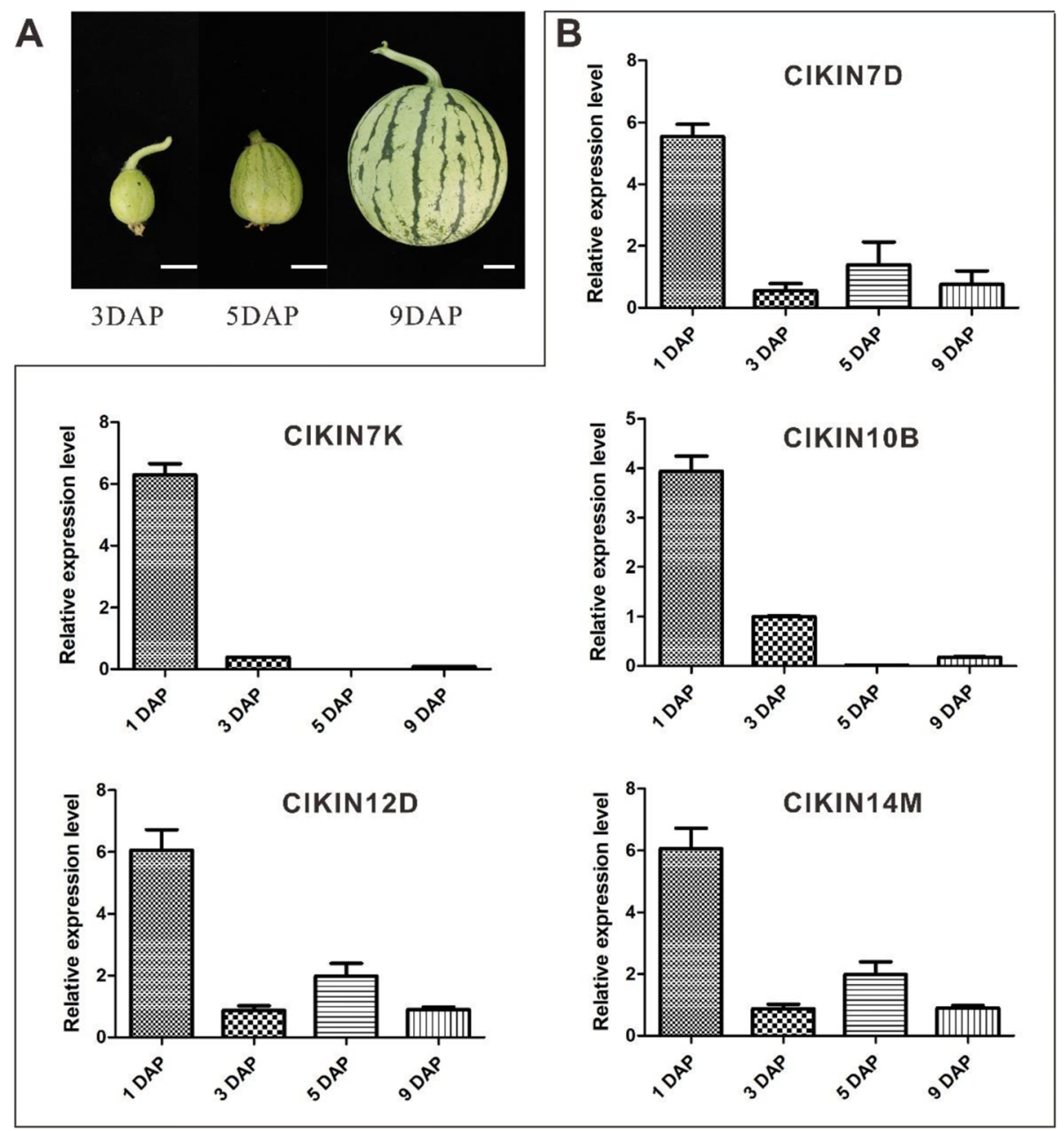

Fig. 8 Expression profiles analysis of 5 CIKINs genes during the early fruit development in Chinese watermelon line 97,103 of round and mediumsize fruit shape. a The morphological characteristics of the watermelon fruits at different days after pollination. 3, 5 and 9 DAP respectively display the days after pollination. $\mathbf{b}$ The expression levels analysis from the 5 CIKINs genes specifically or abundantly expressed in the early fruit development, especially in the fruit at 1DAP. The standard deviations of three biological replicates are represented by the error bars

kinesin genes were responsive to ABA or ETH treatments. Moreover, 23 ClKINs genes were regulated by both $\mathrm{ABA}$ and $\mathrm{ETH}$, but showing very different expression pattern under different hormone treatment. Following ABA treatment, the expression levels of two ClKINs (CIKIN11A and ClKIN7G) were sharply down-regulated (<twofold), whereas the expression levels of 21 ClKINs significantly increased ( $>$ twofold). However, unlike ABA treatment, most of kinesin genes (32 ClKINs) exhibited significant up-regulation in response to ETH stimuli. After ETH treatment, the expression levels of ClKIN7K, ClKIN1OB and ClKIN14M were not changed abruptly, however, ClKIN7D and ClKIN12D exhibited significant up-regulation (> twofold), and interestingly, ClKIN7D was also sharply up-regulated (<twofold) after ABA treatment. The results implied that CIKIN7D and ClKIN12D potentially involved in the regulation of the plant hormones pathway. In general, these detailed expression level analyses implied that ClKINs genes could participate in the regulation of the plant hormones pathway.

\section{Discussion}

Watermelon [Citrullus lanatus (Thunb.) Matsum. \& Nakai] comprises the major cucurbits and is the fifth consumed fruit in the world. It is also one of the most important economic crops grown worldwide. Fruit development traits are the very important agronomic traits in watermelon breeding. The early fruit development in watermelon directly affects the subsequent agronomic traits, including the fruit size, shape and quality. Kinesins are important microtubule-based motor proteins with conserved motor domains among all eukaryotic organisms. They play critical roles in the unidirectional 


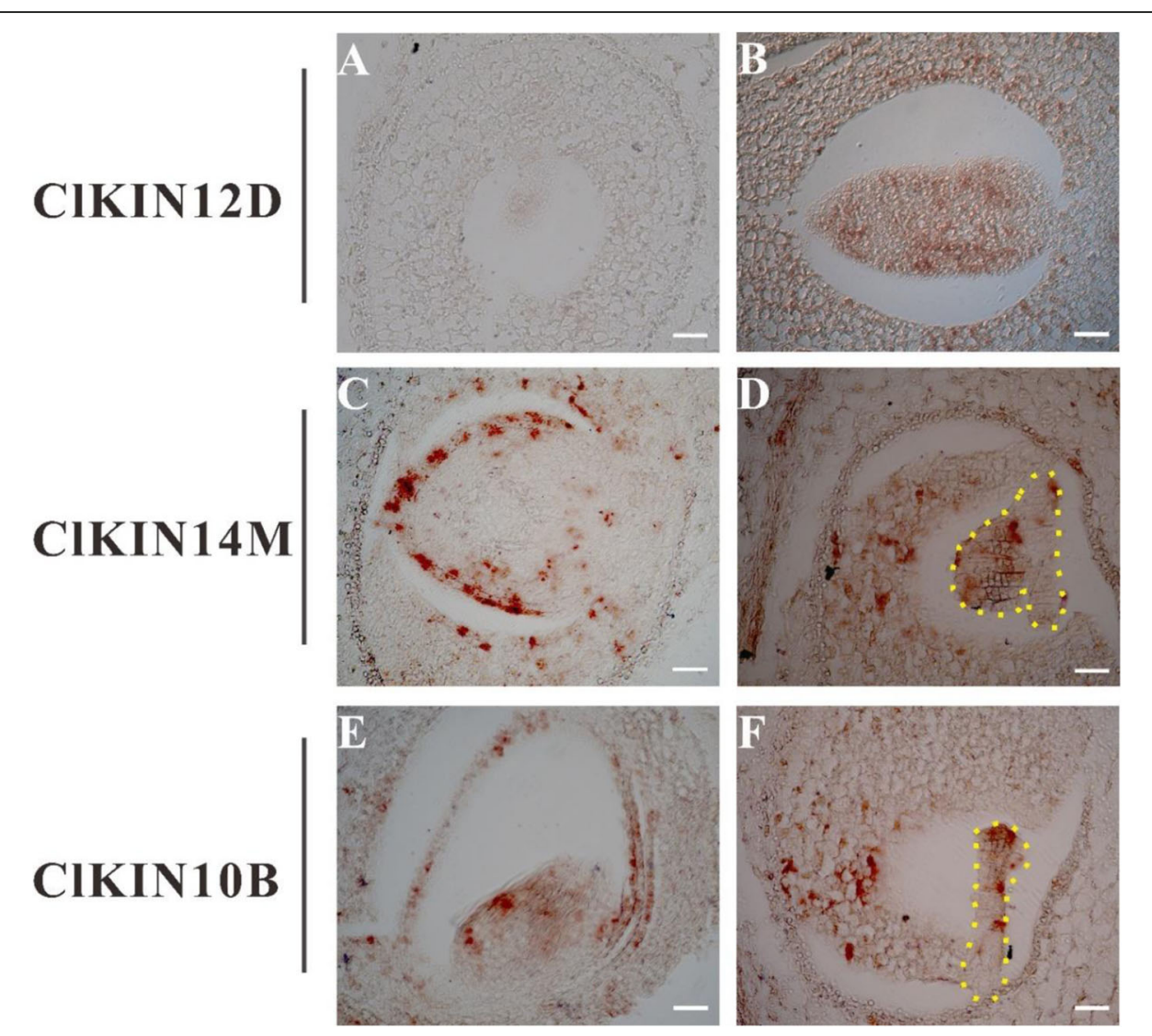

Fig. 9 RNA in situ hybridization of CIKIN10B, CIKIN12D and CIKIN14M in early fruits/seeds. Positive signals (shown in red) are clearly restricted to the seed coat (b, $\mathbf{c}$ and $\mathbf{e}$ ) and embryos ( $\mathbf{d}$ and $\mathbf{f}$ ) of the early fruits. When hybridized with sense probes, no signal is observed (a). The yellow breakpoint lines marked the embryos. Bars $=40 \mu \mathrm{m}$

transport of vesicles and organelles, cytokinesis, signal transduction, morphogenesis, cell division and cell growth in the plant development [38-41]. Furthermore, previous researches have revealed that the kinesin family genes also participated in plant reproductive development [29-31, 42]. Especially, kinesin family genes have been proved to be essential for the regulation of early fruit development in Malus domestica and Cucumis sativus $[15,17]$. Therefore, these works declared the urgency of extensively investigation of kinesin family genes in plants, especially in economic crops, with the expectation to improve crop yield. However, the identification and analysis of detailed expression characteristics and functions of kinesin family genes in watermelon, especially in the fruit reproductive tissues, still remain elusive. With the completion of the C. lanatus genome sequence, the ClKINs genes can be systematically identified and analyzed [43]. In the present study, we have identified 48 kinesin family genes ClKINs in the watermelon genome and comprehensively analyzed these genes for their phylogenetic relationships, chromosomal locations, gene structures, conserved motif distributions, and duplication and syntenic analysis. In addition, we performed the extensive analysis of ClKINs expression patterns in different tissues, at different early fruit developmental stages and in response to hormones treatments. Especially, expression patterns analysis during fruit developmental process elaborated the overall characteristics and the specific dynamics of watermelon kinesin family genes in watermelon development. Conclusively, our work provides clear clues to further investigation of their detailed roles in watermelon reproductive development and response to hormones influence.

\section{Characteristics of kinesin family genes in watermelon}

As described above in results section, some typical conserved motifs for kinesin family proteins exists in most watermelon kinesins. Kinesin motor domain is comprised of a Walk A ATP binding motif "FAYGQTGSGKT" and a microtubule binding domain [44-46]. Microtubule binding domain commonly contains three microtubule binding motifs (SSRSH, xDLAGSE and HxPYR) [32]. Highly conserved peptide sequence "FAYGQTGSGKT" in the ATP-binding motif could be found in all of watermelon kinesins through 


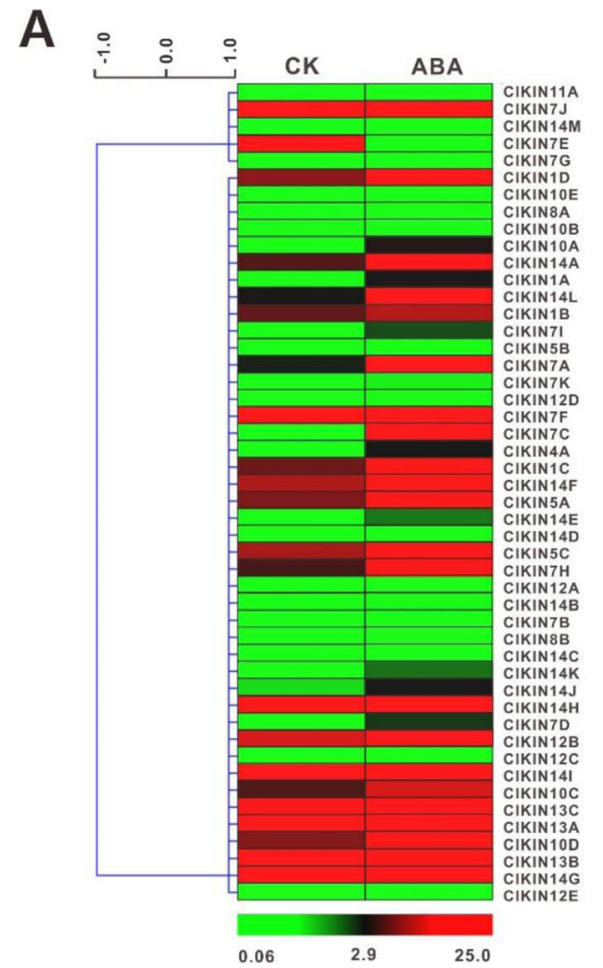

B

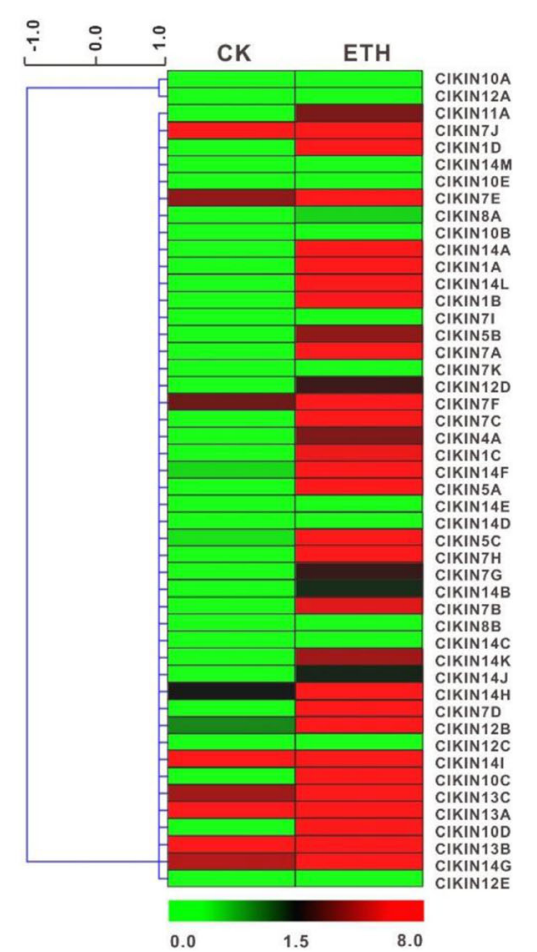

Fig. 10 Expression levels analysis of kinesin family in watermelon under ABA and ETH hormones treatments. a Expression profiles of CIKINs genes under ABA stress treatment visualized as a heat map. $\mathbf{b}$ Expression levels of CIKINs genes under ETH stress treatment. The relative transcript levels were $\log _{2}$ transformed and visualized as a heatmap via Mev6.0, using red to indicate increased expression level and green to indicate decreased expression level (displayed at the bottom)

the alignments of their amino acid sequences, which is responsible for hydrolyze ATP to produce a direct force to travel unidirectionally along microtubule protofilaments and power multiple critical cellular process. The typical microtubule binding site "SSRSH" could be detected in all of kinesins, but the other two microtubule binding motifs "xDLAGSE and HxPYR" could be found in most of kinesins with few exceptions. In particular, only one microtubule binding motif "SSRSH" could be detected in two kinesins CIKIN7C and CIKIN10D, but the other two of three microtubule binding motifs couldn't be found. The results suggested that the microtubule binding site "SSRSH" is the most conserved microtubule binding site. However, whether CIKIN7C and CIKIN10D proteins possess the microtubule binding abilities with only one microtubule binding site needs further verification.

Phylogenetic analysis based on kinesin protein sequences categorized the kinesin genes from watermelon, Arabidopsis and rice into ten families [47]. Interestingly, the number distribution tendency of all these genes from three species was almost the same in the ten groups and did not show distinct monocot or dicot distribution characteristics. The analysis of the consistent tendency showed that the kinesin-14 and kinesin-7 respectively were the first and the second largest group. The kinesin14 family was one well-conserved family and played important roles in chromosome segregation at mitosis and organelle transport [48]. The number of kinesin-14 family members is the maximum both in animals and plants $[48,49]$. The kinesin- 11 subfamily contained the minimum amount of kinesin protein, which had only one kinesin-11 protein in each of the three species. Kinesin11 family members function in signal transduction or divergent catalytic core and are rarely found. In addition, because the kinesin-2, 3, and 9 subfamilies are absent from land plants, the watermelon kinesin superfamily lacks the three subfamilies [50]. The results of phylogenetic analysis implied that kinesin family genes were spatially and functionally conserved in some essential developmental processes in different plant taxa.

\section{Essential roles of kinesin family genes in early fruit development}

Previous microarray and expression profiling analysis have revealed that some kinesin genes were necessary for early fruit development in apple and cucumber [15, $17,18,51]$. However, the exact roles of kinesin genes in the process of early fruit development are still unknown in most economic species, including watermelon. 
Therefore, the expression profiles of kinesin family genes in early fruit development were comprehensively analyzed. qRT-PCR results demonstrated that the transcripts of most kinesin genes could be detected in early developmental fruits at different development stages. A striking feature was that the expression levels of most kinesin genes were higher in fruits at early development stages and then sharply decreased at fruit maturation and ripening. Studies of early fruit development in cucurbits showed that the early fruit growth is primarily due to cell number increments, or in the other words, primarily driven by cell division [52]. Moreover, the period of rapid cell division was accompanied by increased peak expression of microtubule related kinesin genes [18]. Microtubules facilitate alignment of chromosomes at the spindle equator in mitosis [53]. Therefore, the high expression level of kinesin genes in the early fruit development stages may regulate chromosome organization during mitosis via regulation of cytoskeleton and microtubule dynamics and finally caused the change of the cell amounts or sizes [53].

Which developmental process do the watermelon kinesin genes regulate to ultimately control the early fruit development? This question is intriguing and needs to be characterized in future. The watermelon fruit as well as tomato fruit are classified as a berry fruit because the thick pericarp encloses many seeds. The edible parts of two kinds of fruits are either mainly composed of placentas or develop and differentiate from the placenta tissues [21]. The comprehensive tissue-specific transcriptome analysis revealed that the kinesin gene SPPAKRP1 showed peak expression in the placenta tissue during the early stage of fruit development in Solanum pimpinellifolium, a wild cultivated tomato $[19,20]$. This suggested that the tomato kinesin gene SpPAKRP1 could be involved in the early fruit development by regulating the placenta tissue development. This implies that the watermelon kinesin genes ClKINs, specifically or abundantly expressed in the early fruit development stage, could also control the early fruit development via regulating the placenta tissue development. This provided an ideal entry point to study the molecular mechanism of early fruit development through analyzing the role in the placenta development. Nevertheless, the exact roles of these kinesin genes need to be further studied and confirmed.

\section{Potential roles of kinesin family genes in response to hormones treatments}

Plant hormones are a group of small signal molecules which have been approved to play essential roles in different processes of plant growth and development. The expression levels of a larger number of genes are known to regulated by different plant hormones. Previous studies have discovered the contribution of hormones such as ethylene (ETH) in sex determination and development of sex-specific floral organs in the Cucurbitaceae $[54,55]$. In addition, study has indicated that kinesin-4 gene OsGDD11 is involved in the signaling pathways of plant hormone [27]. More importantly, in cucurbits crops, pollination was believed to be the key process to release hormonal enzymes, most specifically auxin, which in turns to stimulate fruit enlargement [23]. Early studies demonstrated that plant hormones have been implicated to facilitate early fruit development in cucurbits, although there is debate as to which hormones are most critical [23, 56]. Mitotic kinesins play important roles in chromosome organization during mitosis in developing cucurbits cucumber fruits $[17,53]$. These studies implied that there is a connection between plant hormones and kinesins. The fact has been first verified in rice, in which kinesin protein gene $B C 12 / G D D 1$ mediated cell elongation by regulating the hormone GA biosynthesis pathway [27]. In order to further explore the relationships between plant hormones and kinesins in watermelon, in our present work, the relative expression levels of kinesin genes after hormones treatments were investigated. The results showed that the transcription levels of most kinesin genes changed after hormones treatments, indicating their critical roles in response to different hormones. Although some genes could respond to the same hormones, some other members of kinesin family genes showed their roles differentially in response to certain hormones. Interestingly, ClKIN7E and CIKIN7G were down-regulated after ABA treatment, which is quite different from other kinesin genes, implying their unique roles in response to $\mathrm{ABA}$ hormone treatment. Taken together, the data provided useful clues for the further investigations of molecular mechanism of kinesins in response to plant hormones during the plant development process.

\section{Conclusions}

In conclusion, $48 \mathrm{ClKINs}$ genes were identified in $\mathrm{C}$. lanatus at the whole-genome level. These genes were categorized into 10 subfamilies. The chromosomal locations, exon/intron structures, conserved motif distributions, and syntenic analysis of kinesin family members in C. lanatus were determined. Comprehensive analysis and expression profiling of ClKINs genes were performed to determine the potential functions in early fruit development and in response to hormones stimuli. Furthermore, detailed expression analysis revealed the tissue-specific and highly expression pattern of ClKINs genes. Finally, 5 ClKINs genes, including ClKIN7D, ClKIN7K, ClKIN1OB, ClKIN12D and ClKIN14M, demonstrated relatively specifically and highest expression level simultaneously in the early fruit developmental, 
indicating their important roles in the early fruit developmental.

\section{Methods}

\section{Identification of kinesin gene family in Citrullus lanatus}

All BLAST searches were conducted in the watermelon genome database (Cucurbit Genomics Database, http:// www.icugi.org/) by using three motor domain sequences from the KHC (N-terminus motor in human), KIF2 (internal motor in mouse), and KCBP (C-terminus motor in Arabidopsis) as queries. Sixty-three candidate genes generated by using an E-value cut-off of 1, which contained kinesins and some unrelated proteins. In addition, Hidden Markov Model (HMM) profiles of the motor domain (PF00225) was downloaded from the Pfam database (http://pfam.xfam.org/). Then HMMER 3.0 software was used to search for kinesins. Motor domain analysis in SMART (http://smart.embl-heidelberg.de/) and INTERPROSCAN (http://www.ebi.ac.uk/interpro/) were performed and the proteins without conserved motor domain were deleted. Finally, the candidate kinesin genes in watermelon were further analyzed with the online tools ExPASY (http://www.expasy.org/tools/) to predict the isoelectric point (PI) and molecular weight (MW).

\section{Chromosome localization analysis of watermelon kinesin genes}

The chromosome locations information of all ClKINs genes were downloaded from watermelon genomics database. The information, including localizations and length of the chromosomes, were visualized by MapChart online software.

\section{Phylogenetic analysis of kinesin genes}

Kinesin amino acid sequences from $C$. lanatus with $A$. thaliana, $O$. sativa and Solanum lycopersicum were aligned using the software Muscle with the default multiple alignment parameters. The phylogenetic trees were constructed via MEGA 6.06 using the neighbor joining method. The bootstrap replicates test value was set as 1000.

\section{Gene structures and conserved motifs analysis of kinesin proteins}

The ClKINs gene structures were visualized by using the program GSDS2.0 (Gene Structure Display Server, http://gsds.cbi.pku.edu.cn/). The conserved motifs in $C$. lanatus kinesin proteins were identified by using the program MEME (Multiple Em for Motif Elicitation, http://meme-suite.org/tools/meme). The maximum number of motifs was set to 7 and the others were default.

\section{Syntenic analysis of watermelon CIKINs genes}

The homolog pairs between $C$. lanatus and A. thaliana were identified using the BLASTp program. GFF files serves as input documents for MCScanX to analyze the synteny relationship [57]. The analysis result was visualized using the software CIRCOS (http://circos.ca/).

\section{Plant materials and hormones treatments}

97,103 is an inbred line provided by Dr. Yong Xu from Beijing Key Laboratory of Vegetable Germplasm Improvement. YL watermelon materials were collected from the desert area in Yulin, Shaanxi Province, China. Under normal conditions, various tissues including root, stem, leaf, female flower, male flower and fruits at different days after pollination of $C$. lanatus were collected for RNA extraction. The watermelon plants were grown under natural light with temperatures of $28-35{ }^{\circ} \mathrm{C} / 16$ $20{ }^{\circ} \mathrm{C}$ (day/night) in a greenhouse in spring. For hormones treatments, four-week-old seedlings after sowing were used phytohormones treatments. The leaves of the seedlings were sprayed with $100 \mu \mathrm{M}$ Abscisic acid (ABA) [58] and $10 \mathrm{mM}$ Ethephon (ETH) [59] and collected after $12 \mathrm{~h}$ treatments. The control seedlings were sprayed with the same solutions except for corresponding hormones. The taken samples with three biological replicates were immediately frozen in liquid nitrogen and stored at $-80{ }^{\circ} \mathrm{C}$ before RNA extraction.

\section{RNA extraction and qRT-PCR}

The total RNA of virous tissues were extracted using the Quick RNA isolation kit (Huayueyang Biotechnologies Co. Ltd, Beijing, China) according to the manufacturer's instructions. The first-strand cDNA was synthesized with $1 \mu \mathrm{g}$ total RNA using SuperScript III transcriptase (Invitrogen).

Quantitative reverse transcription PCR (qRT-PCR) was conducted on an ABI StepOnePlus machine using SYBR Premix Ex $\mathrm{Taq}^{\mathrm{Tm}}$ (TaKaRa). Three independent biological repeats were performed for each ClKIN gene. Specific primers for all ClKINs genes were designed using Primer3Plus online software (http://www. bioinformatics.nl/cgi-bin/primer3plus/primer3plus.cgi) and listed in Supplementary Table S2. The relative expression levels of ClKINs genes were normalized against that of the watermelon ACTIN gene (gene ID: Cla007792) transcript.

\section{RNA in situ hybridization}

To analyze the tissue expression patterns of kinesin genes in fruits at the early fruit development stage, 2-, 3and 5-DAP fruits of watermelon YL line were used for RNA in situ hybridization as described in our previous work [42]. The fruits were fixed for $16 \mathrm{~h}$ in $4 \%$ paraformaldehyde solution with $0.1 \%$ Triton $\mathrm{X}-100$ and $0.1 \%$ 
Tween 20 in PBS. After dehydration using graded ethanol and vitrification by dimethylbenzene, the samples were embedded in paraffin. The paraffin blocks were cut into $8 \mu \mathrm{m}$ thick sections. The reaction results of in situ hybridization signals were detected as purple red color by adding the substrates nitroblue tetrazolium/5-bromo4-chloro-3-indolyl-phosphate (NBT/BCIP). The hybridization signals were observed and photographed with an Axio imager M2 microscope (Zeiss).

\section{Abbreviations}

Cl: Citrullus lanatus; KIN: Kinesin; MT: Microtubule; qRT-PCR: Quantitative reverse transcription PCR; PAKRP: Phragmoplast-associated kinesin-related protein

\section{Supplementary Information}

The online version contains supplementary material available at https://doi. org/10.1186/s12870-021-02988-6.

Additional file 1: Figure S1. Phylogenetic tree of kinesin genes from C. lanatususing neighbor-joining method. Figure S2. Phylogenetic tree of kinesin genes from C. lanatusand and A. thaliana using neighbor-joining method. Figure S3. Phylogenetic tree of kinesin genes from C. lanatusand and S. lycopersicum using neighbor-joining method. Neighborjoining phylogenetic tree of the kinesin family. The different kinesin subfamily was marked with different color, respectively. Figure S4. Comparative expression analysis of 5 CIKINsgenes in seed at different days after pollination by qRT-PCR. CIACTIN gene was used for normalization of quantitative RT-PCR results. The standard deviations of three biological replicates are represented by the error bars. Table S1. Kinesin gene family members identified in Citrullus lanatus. Table S2. The specific primers for qRT-PCR of 48 CIKINsgenes.

\section{Acknowledgements}

Not applicable.

\section{Permission statement}

We ensure that we have the permission to collect the plant samples in this research.

\section{Authors' contributions}

TS and YL were responsible for the data analysis and experimental design. TS and $Y L$ wrote the manuscript. TS, JJ, XG, WT, LQ, CX, LM, LZ, LM and YL were responsible for the programs and the manuscript revision. All authors have commented, read and approved the final manuscript.

\section{Funding}

The authors gratefully acknowledge the financial supports of the Talented Program (A279021801), the Fundamental Research Fund from the Northwest A\&F University (Z111021903), the Natural Science Foundation of Shaanxi Province (2021JM-089), Domestic Doctoral Program of Shaanxi Province (F2020221012, F2020221013) and the Doctoral Scientific Research Fund of Northwest A\&F University $(2452018069,2452018113)$. The funding agencies had no role in the design, analysis, interpretation of the data or writing of the manuscript.

\section{Availability of data and materials}

The datasets generated during the current study are available in the GenBank repository, http://www.ncbi.nlm.nih.gov/Genbank and the accession numbers are as follows: CIKIN1A (MW882942), CIKIN1B (MW882943), CIKIN1C (MW889992), CIKIN1D (MW889993), CIKIN4A(MW889994), CIKIN5A(MW889995), CIKIN5B (MW889996), CIKIN5C (MW889997), CIKIN7A(MW889998), CIKIN7B(MW889999), CIKIN7C(MW890000), CIKIN7D(MW890001), CIKIN7E(MW890002), CIKIN7F (MW958182), CIKIN7G (MW958183), CIKIN7H (MW958184), CIKIN7I (MW958185), CIKIN7J (MW958186), CIKIN7K (MW958187), CIKIN8A (MW958188), CIKIN8B (MW958189), CIKIN10A (MW958190), CIKIN10B (MW958191), CIKIN10C
(MW958192), CIKIN10D (MW958193), CIKIN10E (MW958194), CIKIN11A (MW958195), CIKIN12A (MW958196), CIKIN12B (MW958197), CIKIN12C (MW958198), CIKIN12D (MW958199), CIKIN12E (MW958200), CIKIN13A (MW958201), CIKIN13B (MW958202), CIKIN13C (MW958203), CIKIN14A (MW958204), CIKIN14B (MW958205), CIKIN14C (MW958206), CIKIN14D (MW958207), CIKIN14E (MW958208), CIKIN14F (MW958209), CIKIN14G (MW958210), CIKIN14H (MW958211), CIKIN14I (MW958212), CIKIN14J (MW958213), CIKIN14K (MW958214), CIKIN14L (MW958215), CIKIN14M (MW958216).

\section{Declarations}

Ethics approval and consent to participate

Not applicable.

\section{Consent for publication}

Not applicable.

\section{Competing interests}

The authors declare that they have no competing interests.

Received: 10 September 2020 Accepted: 26 April 2021

Published online: 10 May 2021

\section{References}

1. Richardson DN, Simmons MP, Reddy AS. Comprehensive comparative analysis of kinesins in photosynthetic eukaryotes. BMC Genomics. 2006;7:18.

2. Vale RD, Reese TS, Sheetz MP. Identification of a novel force-generating protein, kinesin, involved in microtubule-based motility. Cell. 1985;42(1):3950.

3. Sablin EP, Kull FJ, Cooke R, Vale RD, Fletterick RJ. Crystal structure of the motor domain of the kinesin-related motor ncd. Nature. 1996;380(6574): $555-9$.

4. Hirokawa N, Pfister KK, Yorifuji H, Wagner MC, Brady ST, Bloom GS. Submolecular domains of bovine brain kinesin identified by electron microscopy and monoclonal antibody decoration. Cell. 1989;56(5):867-78.

5. Kikkawa M, Sablin EP, Okada Y, Yajima H, Fletterick RJ, Hirokawa N. Switchbased mechanism of kinesin motors. Nature. 2001;411(6836):439-45.

6. Nitta R, Kikkawa M, Okada Y, Hirokawa N. KIF1A alternately uses two loops to bind microtubules. Science. 2004;305(5684):678-83.

7. Diefenbach RJ, Mackay JP, Armati PJ, Cunningham AL. The C-terminal region of the stalk domain of ubiquitous human kinesin heavy chain contains the binding site for kinesin light chain. Biochemistry. 1998;37(47): 16663-70.

8. Kanai Y, Dohmae N, Hirokawa N. Kinesin transports RNA: isolation and characterization of an RNA-transporting granule. Neuron. 2004;43(4):513-25.

9. Endow SA, Waligora KW. Determinants of kinesin motor polarity. Science. 1998:281(5380):1200-2.

10. Lawrence CJ, Dawe RK, Christie KR, Cleveland DW, Dawson SC, Endow SA, Goldstein LS, Goodson HV, Hirokawa N, Howard J, et al. A standardized kinesin nomenclature. J Cell Biol. 2004;167(1):19-22.

11. Reddy AS. Molecular motors and their functions in plants. Int Rev Cytol. 2001;204:97-178.

12. McDonald HB, Stewart RJ, Goldstein LS. The kinesin-like ncd protein of Drosophila is a minus end-directed microtubule motor. Cell. 1990;63(6): 1159-65.

13. Walker RA, Salmon ED, Endow SA. The Drosophila claret segregation protein is a minus-end directed motor molecule. Nature. 1990;347(6295):780-2.

14. Endow SA, Kang SJ, Satterwhite LL, Rose MD, Skeen VP, Salmon ED. Yeast Kar3 is a minus-end microtubule motor protein that destabilizes microtubules preferentially at the minus ends. EMBO J. 1994;13(11):2708-13.

15. Lee YP, Yu GH, Seo YS, Han SE, Choi YO, Kim D, Mok IG, Kim WT, Sung SK. Microarray analysis of apple gene expression engaged in early fruit development. Plant Cell Rep. 2007;26(7):917-26.

16. Soria-Guerra RE, Rosales-Mendoza S, Gasic K, Wisniewski ME, Band M, Korban SS. Gene Expression is Highly Regulated in Early Developing Fruit of Apple. Plant Mol Biol Report. 2011;29(4):885-97.

17. Yang XY, Wang Y, Jiang WJ, Liu XL, Zhang XM, Yu HJ, Huang SW, Liu GQ. Characterization and expression profiling of cucumber kinesin genes during early fruit development: revealing the roles of kinesins in exponential cell production and enlargement in cucumber fruit. J Exp Bot. 2013;64(14):4541-57. 
18. Jiang L, Yan S, Yang W, Li Y, Xia M, Chen Z, Wang Q, Yan L, Song X, Liu R et al. Transcriptomic analysis reveals the roles of microtubule-related genes and transcription factors in fruit length regulation in cucumber (Cucumis sativus L.). Sci Rep 2015; 5:8031.

19. Breyne P, Dreesen R, Vandepoele K, De Veylder L, Van Breusegem F, Callewaert L, Rombauts S, Raes J, Cannoot B, Engler G, et al. Transcriptome analysis during cell division in plants. Proc Natl Acad Sci U S A. 2002;99(23): 14825-30.

20. Pattison RJ, Csukasi F, Zheng Y, Fei Z, van der Knaap E, Catala C Comprehensive Tissue-Specific Transcriptome Analysis Reveals Distinct Regulatory Programs during Early Tomato Fruit Development. Plant Physiol. 2015;168(4):1684-701.

21. Gillaspy G, Ben-David H, Gruissem W. Fruits: a developmental perspective. Plant Cell. 1993;5(10):1439-51.

22. Monforte AJ, Diaz A, Cano-Delgado A, van der Knaap E. The genetic basis of fruit morphology in horticultural crops: lessons from tomato and melon. J Exp Bot. 2014;65(16):4625-37.

23. Fu FQ, Mao WH, Shi K, Zhou YH, Asami T, Yu JQ. A role of brassinosteroids in early fruit development in cucumber. J Exp Bot. 2008;59(9):2299-308.

24. Ando K, Carr KM, Grumet R. Transcriptome analyses of early cucumber fruit growth identifies distinct gene modules associated with phases of development. BMC Genomics. 2012;13:518.

25. Sazuka T, Aichi I, Kawai T, Matsuo N, Kitano H, Matsuoka M. The rice mutant dwarf bamboo shoot 1: a leaky mutant of the NACK-type kinesin-like gene can initiate organ primordia but not organ development. Plant Cell Physiol. 2005;46(12):1934-43.

26. Zhang M, Zhang B, Qian Q, Yu Y, Li R, Zhang J, Liu X, Zeng D, Li J, Zhou Y. Brittle Culm 12, a dual-targeting kinesin-4 protein, controls cell-cycle progression and wall properties in rice. Plant J. 2010;63(2):312-28.

27. Li J, Jiang J, Qian Q, Xu Y, Zhang C, Xiao J, Du C, Luo W, Zou G, Chen M, et al. Mutation of rice BC12/GDD1, which encodes a kinesin-like protein that binds to a GA biosynthesis gene promoter, leads to dwarfism with impaired cell elongation. Plant Cell. 2011;23(2):628-40.

28. Kong Z, loki M, Braybrook S, Li S, Ye ZH, Julie Lee YR, Hotta T, Chang A, Tian J, Wang $G$, et al. Kinesin-4 functions in vesicular transport on cortical microtubules and regulates cell wall mechanics during cell elongation in plants. Mol Plant. 2015;8(7):1011-23.

29. Kitagawa K, Kurinami S, Oki K, Abe Y, Ando T, Kono I, Yano M, Kitano H, Iwasaki Y. A novel kinesin 13 protein regulating rice seed length. Plant Cell Physiol. 2010;51(8):1315-29.

30. Wu T, Shen Y, Zheng M, Yang C, Chen Y, Feng Z, Liu X, Liu S, Chen Z, Lei C, et al. Gene $S G L$, encoding a kinesin-like protein with transactivation activity, is involved in grain length and plant height in rice. Plant Cell Rep. 2014; 33(2):235-44.

31. Tian S, Wu J, Li F, Zou J, Liu Y, Zhou B, Bai Y, Sun MX. NtKRP, a kinesin-12 protein, regulates embryo/seed size and seed germination via involving in cell cycle progression at the G2/M transition. Sci Rep. 2016:6:35641.

32. Lee $Y R$, Liu B. Identification of a phragmoplast-associated kinesin-related protein in higher plants. Curr Biol. 2000;10(13):797-800.

33. Vale RD, Fletterick RJ. The design plan of kinesin motors. Annu Rev Cell Dev Biol. 1997:13:745-77.

34. Vision TJ, Brown DG, Tanksley SD. The origins of genomic duplications in Arabidopsis. Science. 2000;290(5499):2114-7.

35. Cannon SB, Mitra A, Baumgarten A, Young ND, May G. The roles of segmental and tandem gene duplication in the evolution of large gene families in Arabidopsis thaliana. BMC Plant Biol. 2004;4:10.

36. Okello RCO, Heuvelink E, de Visser PHB, Struik PC, Marcelis LFM. What drives fruit growth? Funct Plant Biol. 2015;42(9):817-27.

37. Guo SG, Liu JA, Zheng Y, Huang MY, Zhang HY, Gong GY, He HJ, Ren Y, Zhong SL, Fei ZJ, et al. Characterization of transcriptome dynamics during watermelon fruit development: sequencing, assembly, annotation and gene expression profiles. BMC Genomics. 2011:12:1-13.

38. Sharp DJ, Brown HM, Kwon M, Rogers GC, Holland G, Scholey JM. Functional coordination of three mitotic motors in Drosophila embryos. Mol Biol Cell. 2000;11(1):241-53.

39. Reddy AS, Day IS. Kinesins in the Arabidopsis genome: a comparative analysis among eukaryotes. BMC Genomics. 2001;2:2.

40. Lee YR, Liu B. Cytoskeletal motors in Arabidopsis. Sixty-one kinesins and seventeen myosins. Plant Physiol 2004;136(4):3877-83.

41. Hirokawa N, Noda Y, Tanaka $Y$, Niwa S. Kinesin superfamily motor proteins and intracellular transport. Nat Rev Mol Cell Biol. 2009;10(10):682-96.
42. Tian S, Wu J, Liu Y, Huang X, Li F, Wang Z, Sun MX. Ribosomal protein NtRPL17 interacts with kinesin-12 family protein NtKRP and functions in the regulation of embryo/seed size and radicle growth. J Exp Bot. 2017;68(20): 5553-64.

43. Guo S, Zhang J, Sun H, Salse J, Lucas WJ, Zhang H, Zheng Y, Mao L, Ren Y, Wang $Z$, et al. The draft genome of watermelon (Citrullus lanatus) and resequencing of 20 diverse accessions. Nat Genet. 2013;45(1):51-8.

44. Hirokawa N. Kinesin and dynein superfamily proteins and the mechanism of organelle transport. Science. 1998;279(5350):519-26.

45. Vale RD, Fletterick RJ. The design plan of kinesin motors. Annu Rev Cell Dev Bi. 1997:13:745-77.

46. Kim AJ, Endow SA. A kinesin family tree. J Cell Sci. 2000;113(21):3681-2.

47. Huang Y, Wang H, Huang X, Wang Q, Wang J, An D, Li J, Wang W, Wu Y. Maize VKS1 regulates mitosis and cytokinesis during early endosperm development. Plant Cell. 2019;31(6):1238-56.

48. Miki H, Okada Y, Hirokawa N. Analysis of the kinesin superfamily: insights into structure and function. Trends Cell Biol. 2005;15(9):467-76.

49. Vanstraelen M, Inze D, Geelen D. Mitosis-specific kinesins in Arabidopsis. Trends Plant Sci. 2006;11(4):167-75.

50. Zhu C, Dixit R. Functions of the Arabidopsis kinesin superfamily of microtubule-based motor proteins. Protoplasma. 2012;249(4):887-99.

51. Malladi A, Johnson LK: Expression profiling of cell cycle genes reveals key facilitators of cell production during carpel development, fruit set, and fruit growth in apple (Malusxdomestica Borkh.). J Exp Bot 2011;62(1):205-19.

52. Sinnott EW. A developmental analysis of the relation between cell size and fruit size in cucurbits. Am J Bot. 1939;26(4):179-89.

53. Ganguly A, Dixit R. Mechanisms for regulation of plant kinesins. Curr Opin Plant Biol. 2013;16(6):704-9.

54. Yamasaki S, Fujii N, Takahashi H. Hormonal regulation of sex expression in plants. Vitam Horm. 2005;72:79-110.

55. Boualem A, Troadec C, Camps C, Lemhemdi A, Morin H, Marie-Agnes S, Fraenkel-Zagouri R, Kovalski I, Dogimont C, Perl-Treves R, et al. A cucurbit androecy gene reveals how unisexual flowers develop and dioecy emerges. Science. 2015;350(6261):688-91.

56. Boonkorkaew P, Hikosaka S, Sugiyama N. Effect of pollination on cell division, cell enlargement, and endogenous hormones in fruit development in a gynoecious cucumber. Sci Hortic. 2008;116(1):1-7.

57. Wang Y, Tang H, Debarry JD, Tan X, Li J, Wang X, Lee TH, Jin H, Marler B, Guo $H$, et al. MCScanX: a toolkit for detection and evolutionary analysis of gene synteny and collinearity. Nucleic Acids Res. 2012;40(7):e49.

58. Song Q, Li D, Dai Y, Liu S, Huang L, Hong Y, Zhang H, Song F. Characterization, expression patterns and functional analysis of the MAPK and MAPKK genes in watermelon (Citrullus lanatus). BMC Plant Biol. 2015;15: 298.

59. Yang $X$, Li H, Yang Y, Wang Y, Mo Y, Zhang R, Zhang Y, Ma J, Wei C, Zhang $X$. Identification and expression analyses of WRKY genes reveal their involvement in growth and abiotic stress response in watermelon (Citrullus lanatus). PLoS ONE. 2018;13(1):e0191308.

\section{Publisher's Note}

Springer Nature remains neutral with regard to jurisdictional claims in published maps and institutional affiliations.

Ready to submit your research? Choose BMC and benefit from:

- fast, convenient online submission

- thorough peer review by experienced researchers in your field

- rapid publication on acceptance

- support for research data, including large and complex data types

- gold Open Access which fosters wider collaboration and increased citations

- maximum visibility for your research: over $100 \mathrm{M}$ website views per year

At BMC, research is always in progress.

Learn more biomedcentral.com/submissions 